\title{
The Construction of China's Images through Multimodal Metaphor: A Case Study of China-related BBC Documentaries
}

\author{
Ping Tang \\ School of Foreign Studies, Guilin University of Technology, Guilin, China \\ Kelin Quan \\ College of International Education, Guilin University of Technology, Guilin, China \\ Jianbin Zhu \\ School of Foreign Studies, Guilin University of Technology, Guilin, China
}

\begin{abstract}
Complementing three theoretical frameworks, conceptual metaphor theory (Lakoff and Johnson 1980) and critical metaphor analysis (Charteris-Black 2004; Musolff 2006, 2016) and multimodality from a cognitive viewpoint (Forceville and Urios-Aparisi 2009; Perez-Sobrina 2017), this study addresses the topic of China's images unfolded in six BBC documentaries that are related to Chinese economy, social life, education, history, folklore, and cuisine respectively. This paper analyzes in detail how the theme metaphors are manifested multimodally through verbal, visual and aural modes and sub-modes with particular focus on how multimodal metaphors construct China's images through the choice of source domains and metaphorical mapping. The significance of the study lies in showing how various modes and sub-modes are used in the source domains as an overall persuasive strategy to manipulate the public's conceptualization of China. In addition, by examining the metaphorical entailments (Lakoff 2002; Johnson 1993, 1983), it illustrates how the media use of conceptual metaphors may become a powerful tool for conveying evaluative ideologies.
\end{abstract}

Index Terms-multimodal metaphor, critical metaphor analysis, BBC documentary, China's images

\section{INTRODUCTION}

As it is playing an increasingly dynamic role in the international arena, China has become a focus of world media. The $\mathrm{BBC}$ is well-reputed as one of the most authoritative media and its documentaries are hugely influential worldwide. However, documentaries not only involve artifice and craft, but also embody "social and political critique, ideology and propaganda" (Aitken, 2006, p. 2).

Some studies have attempted to explore how China's images are built up in BBC documentaries from three perspectives: cross-culture communication (Song 2018); journalism (Xuan and Wang 2019; Xu 2015) and critical discourse analysis (Zhu and Huang 2017). As shown, while the macro scopes like theme, content, plot, narrative characteristics, filming techniques and viewers' reception have been explored to illuminate the relationship between BBC documentaries and China's images, the impact of the micro perspectives such as the utterance of the hosts, background music, colors, captions, graphs and others on the in-depth explanation were largely underrepresented.

Since the ubiquitous use of metaphor is the nature of press communication (de los Ríos, 2010, p. 81-107), those micro elements could be metaphorical. Modern metaphor theory categorizes metaphor as a mechanism of understanding rather than its traditional role as a mere stylistic ornament. In the revolutionary monograph Metaphors We Live By (1980), Lakoff and Johnson provided systematic linguistic evidence that metaphors structure the understanding by a cross-domain conceptual mapping, as proposed by Conceptual Metaphor Theory (Lakoff 1993; Lakoff and Johnson 1980, 1999). Later, Forceville (2006) extends verbal metaphor to multimodal metaphor because metaphorical thought should manifest itself via various modes of communication. Besides the cognitive aspect of metaphor, some scholars strive to investigate the ideological function of metaphor. Charteris-Black (2004) suggests critical metaphor analysis, which gives an insight into the "political and ideological motivations" (p. 29). Maalej (2007), Hart (2008), Musolff (2012) reveal the covert and possibly unconscious intentions of language users at the level of verbal metaphor. Some studies investigate multimodal metaphors from the critical multimodal metaphorical/ metonymic discourse analysis (Hidalgo-Downing and Mujic 2011; Catalano and Wangh 2013; Zhao and Feng 2017).

Thus, an analysis of multimodal metaphors in the documentaries can give an insight to not only how the BBC constructs China's images but also how it influences its audience to perceive China and its people. In this paper, a country's images are a total cognitive and evaluative structure of a country portrayed by outside powers.

\section{RESEARCH METHODOLOGY}


The purpose of the investigation is to answer the following two questions:

1) How do different modes of metaphorical representation contribute to the conceptualization of the images of China?

2) What are the ideological evaluations rendered from the multimodal metaphors?

\section{A. Data Collection}

The data for this study are collected from six China-themed BBC documentaries released since 2012. The researchers contentiously chose the data according to the following criteria:

1) Each documentary should be centered on one specific theme;

2) Each documentary should be well-received by the viewer according to IMDb ratings (>7/10). IMDb is one of the world's most popular and authoritative movie and TV review platform. Then the collection is narrowed down as shown in Table 1.

TABLE 1

MATERIALS FOR THE PAPER

\begin{tabular}{|c|c|c|c|c|c|}
\hline Title & Release time & channel & Runtime & Theme & Rating \\
\hline $\begin{array}{l}\text { Exploring China: A Culinary } \\
\text { Adventure }\end{array}$ & Aug 2012 & BBC 2 & 4 episodes $(4 * 60 \mathrm{~min})$ & Cuisine & 8.3 \\
\hline How China Fooled the World & Feb 2014 & BBC 4 & 1 episode $(1 * 60 \mathrm{~min})$ & Economy & 7.0 \\
\hline $\begin{array}{l}\text { Are Our Kids Tough Enough? } \\
\text { Chinese School }\end{array}$ & Aug 2015 & $\mathrm{BBC} 2$ & 3 episodes $(3 * 60 \mathrm{~min})$ & Education & 7.2 \\
\hline Secrets of China & Aug 2015 & BBC 3 & 3 episodes $(3 * 58 \mathrm{~min})$ & Social life & 8.7 \\
\hline The Story of China & Jan 2016 & BBC 2 & 6 episodes $(6 * 59 \mathrm{~min})$ & History & 8.2 \\
\hline $\begin{array}{l}\text { Chinese New Year: The Biggest } \\
\text { Celebration on Earth }\end{array}$ & Feb 2016 & BBC 2 & 3 episodes $(3 * 59 \min )$ & Folklore & 7.6 \\
\hline
\end{tabular}

\section{B. Theoretical Framework}

Inspired by the previous endeavors (Charteris-Black 2004, Hidalgo-Downing and Mujic 2011; Musolff 2012; Catalano and Wangh 2013, 2016; Zhao and Feng 2017; Perez 2017), the present research is to examine how China's images are built up through $\mathrm{BBC}$ documentaries based on the framework of critical multimodal metaphor analysis:

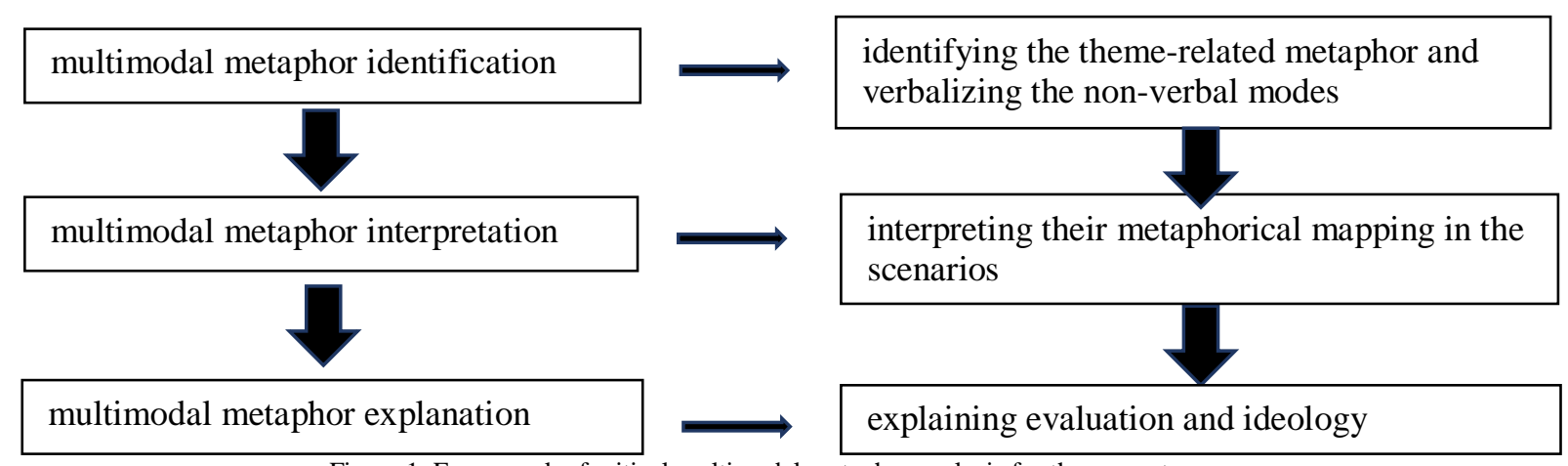

Figure 1. Framework of critical multimodal metaphor analysis for the present paper.

The identification phase lays the foundation for the analysis to follow, so for the sake of reliability, a pilot experiment was conducted among the three researchers. First, one researcher introduced the metaphor identification procedure presented by Perez Sobrino (2017). After that, the five analysts independently annotated the metaphors in How China Fooled the World and then contrasted each other's annotations. Cases of disagreement were resolved through discussion. Finally, the criteria for identification and verbalization were agreed upon:

1) Identification of target domains

The question to formulate this step could be: What aspect of China is being shown? In documentaries, the target domain is usually explicitly represented, which is contrastive to the case in verbal discourse. As for verbalization, one criterion was that only theme-based metaphors were included in a database for later quantitative studies. For example, in Exploring China: A Culinary Adventure, despite various metaphors relating to economy, social events and even history, the researchers exclusively added the cuisine-related metaphors to the self-built corpus.

2) Identification of source domains

The second step looked for modes or submodes that convey China's image, or answers the question What is being said about China? This step incorporated the insights of the independent researchers and the similarly-reached analyses were included in the corpus.

The above protocol was applied to the identification process in the other five documentaries. Then, one researcher verbalized all the consensus metaphors before additional checks and discussions were held to build the corpus of the study. 
In the interpretation phase, statistics were drawn from the distribution of different types of metaphors classified by the interaction of different modes and the metaphorical mapping. Hence, a number of distributions and percentages were calculated for the investigation of these theme multimodal metaphors in ninety-one differential settings. In an additional note, it was necessary to acknowledge the crucial role that metonymy played in the data and thus a brief discussion of the metaphor \& metonymy interactions would be found in the paper. Since this paper's purpose was to highlight the importance of metaphor, the focus was on the metaphors.

Finally, in reference to the representation and mapping characteristics of the specific genre concluded above, the researchers determined how the identified multimodal cognitive devices help shape ideology. The theme conceptual metaphors were evaluated to examine the negativity of China's images and the misreading of Chinese culture. To avoid the subjectivity, triangulation occurred among researchers.

\section{Metaphorical Representation of Multimodal Metaphors}

After brain-storming and triangulation, seventeen theme metaphors are summarized in ninety-one different settings. For the sake of fluency and observing the principle of economy, the verbalization of those metaphors in different arenas is provided in the Appendix. Concerning the fact that different directors had their preferences for creating artistic and dramatic effects, frequency is calculated not based on the metaphors but settings so as to obtain a more comprehensive and objective view of the multimodal representation of metaphors in the particular genre of documentary. All the metaphors are analyzed through identification of source domain, target domain, mappings across relevant modes, which in this paper arrives at the following list: 1) the verbal mode, involving the speech of presenters, interviewees and voice-overs; 2) the visual mode, including moving images, pictorial signs captions, colors and camera perspectives; 3 ) the aural mode, i.e. non-verbal sound, including background music, dubbing sound and natural sound. The categorization is based on what modes are involved in the two separate domains.

\section{A. Overview of Multimodal Metaphorical Representation}

In reference to classification method of multimodal metaphors employed by Yu (2013) and Liu (2017), the researchers analyze the corpus and summarize the main metaphorical representation in BBC documentaries (see table 2).

TABLE 2

THE Multimodal METAPHORICAL REPRESENTATION IN BBC DOCUMENTARIES

\begin{tabular}{|c|c|c|}
\hline Category & Representation & Instantiation \\
\hline Type I & verbal, visual, aural(S)—verbal, visual (T) & $\begin{array}{l}\text { CHINESE ECONOMY IS MOVEMENT } \\
\text { CHINESE ECONOMY IS DOWN } \\
\text { CHINESE INVESTMENT IS BINGE } \\
\text { CHINESE CREDIT IS GAMBLE } \\
\text { CHINESE MARRIAGE IS SHOW } \\
\text { CHINESE LIFE IS FLOATING WATER } \\
\text { THE WEST IS KNOWLEDGE WHILE CHINA IS } \\
\text { ILLITERACY }\end{array}$ \\
\hline Type II & verbal, visual, aural(S) —implied(T) & $\begin{array}{l}\text { THE DIFFERENCE BETWEEN CHINESE AND } \\
\text { BRITISH EDUCATION SYSTEM IS CONFLICT } \\
\text { CHINESE WOMEN EAGER FOR MARRIAGE ARE } \\
\text { DOLLS }\end{array}$ \\
\hline Type III & verbal, aural(S)—verbal, visual $(\mathrm{T})$ & CHINESE SCHOOL IS MILITARY CAMP \\
\hline Type IV & verbal, visual(S)—verbal, visual, aural (T) & CHINESE KITCHEN IS BATTLEFIELD \\
\hline Type V & verbal(S)--verbal, visual(T) & $\begin{array}{l}\text { CHINESE MARRIAGE IS BUSINESS } \\
\text { CHUNYUN IS MIGRATION } \\
\text { NEW YEAR CELEBRATION IS PARTY }\end{array}$ \\
\hline Type VI & verbal, visual, aural (S)--verbal, visual, aural (T) & CHINESE HISTORY IS CYCLE \\
\hline Type VII & verbal, aural $(\mathrm{S})$--visual, aural $(\mathrm{T})$ & CHINESE CLASS IS REPETITIVE DRILL \\
\hline Type VIII & verbal(S) — verbal, visual, aural (T) & CHINESE GAMING IS ESCAPING \\
\hline Type IX & verbal, visual, aural $(\mathrm{S})--\operatorname{verbal}(\mathrm{T})$ & CHINESE CREDIT IS GAMBLE \\
\hline Type X & implied(S) — verbal, visual, aural (T) & CHINESE GAMING IS ESCAPING \\
\hline Type XI & implied(S)—verbal, visual(T) & $\begin{array}{l}\text { CHIESE WOMEN EAGER FOR MARRIAGE ARE } \\
\text { DOLLS }\end{array}$ \\
\hline
\end{tabular}

In a total of ninety-one metaphor settings where there are eight mono-mappings and eighty-three multi-mappings (see the Appendix), the percentage of multi-modal mappings is $91 \%$. It is safe to conclude that metaphors in BBC documentaries are a multimodal phenomenon. For these multimodal metaphors, they are distributed as the following charts: 


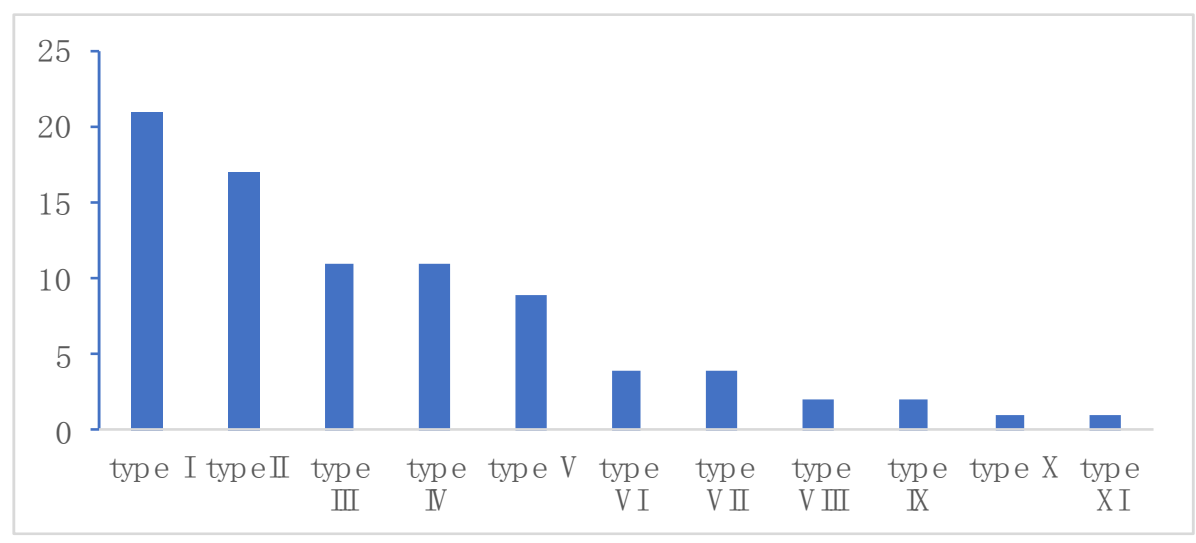

Figure 2. Tokens of different representations

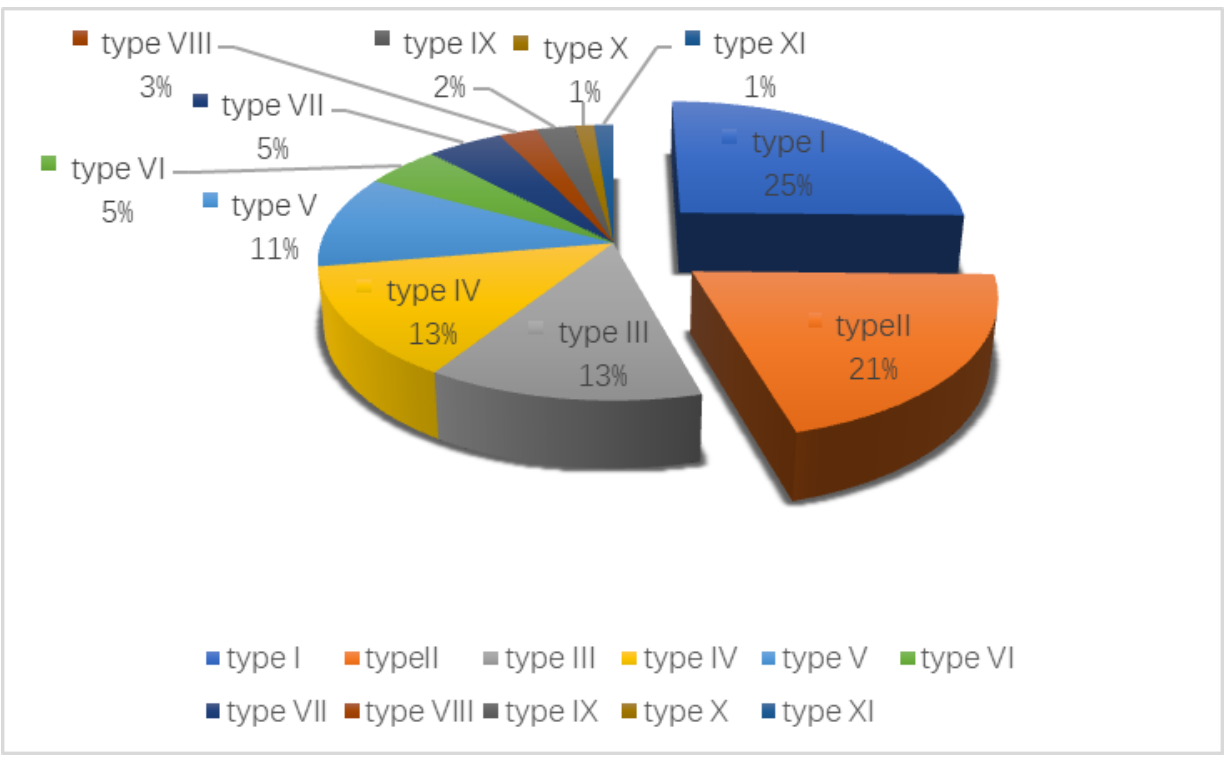

Figure 3. Percentages of different representations.

As is described in the data, in terms of domains, 53\% multi-mappings rely on interplay of the verbal, visual and aural modes to trigger the source domain whereas the target domain is mainly depicted through the mixture of verbal and visual modes, accounting for $51 \%$. In terms of representation of source domain, type I stands out as the most salient representation, accounting for one fourth of the total, which is closely followed by type II. The other three types, type III, type IV of three-mode mapping and type $\mathrm{V}$ of two-mode mapping each occupies more than $10 \%$ of the total representation. The lowest percentages are type $\mathrm{X}$ and type XI.

The representation of the target may echo the goal of the specific genre of documentaries where the topic is generally unveiled explicitly by the presenter and the images at the very beginning of each documentary. On the contrary, the source domains might be hidden in music, camera shots, angles cutting and editing. In the verbal mode, presenters' speaking greatly contributes to the source domain.

\section{B. Instantiation of Multimodal Metaphors}

To answer the question how multimodal metaphors are manifested cross-modally, this paper is going to explore in details the categories whose percentage above $20 \%$. Namely, type I and type II are to be elaborated with typical examples in terms of representation of their source and target domains. Each type of metaphor is to be explored with introduction of its synopsis, interaction of different modes and relationship between domains.

1. Analysis of Type I

The most pervasive representation is the three modes of the source interplaying with verbal and visual modes of the target, with a portion of $25 \%$ in all multi-modal mappings.

An illustrative case is to be found in an excerpt from How China Fooled the World. On 9 November 2008, in face of global financial crisis, the State Council of China approved a plan to invest 4 trillion yuan in infrastructure and social welfare in the next five years. The selected clip concerning the economic stimulus plan can be seen in Table 3 . 
TABLE 3.

ELEMENTS OF THE CM: CHINESE INVESTMENT IS ACCELERATOR BUTTON.

\begin{tabular}{|c|c|c|c|c|}
\hline Place & Settings & Verbal & Visual & Aural \\
\hline \multirow{3}{*}{$\begin{array}{l}\text { How China } \\
\text { Fooled the } \\
\text { World } \\
\text { 11:33-13:48 }\end{array}$} & \multirow{3}{*}{$\begin{array}{l}\text { China } \\
\text { unveiling its } \\
4000 \text { billion } \\
\text { rescue plan in } \\
2008\end{array}$} & $\begin{array}{l}\text { commentator: "hit the } \\
\text { accelerator button" }\end{array}$ & low camera angle of buildings; interviews with experts & $\begin{array}{l}\text { fast-paced } \\
\text { music }\end{array}$ \\
\hline & & $\begin{array}{l}\text { presenter: "off the scale"; } \\
\text { "construction binge" }\end{array}$ & building construction with a time lapse effect & \\
\hline & & $\begin{array}{l}\text { voice-over: "a new skyscraper } \\
\text { every five day"; "more than } 30 \\
\text { new airports"; "metro systems } \\
\text { underway in } 25 \text { cities"; "over } \\
6000 \text { miles of high-speed } \\
\text { railway track"; "the three } \\
\text { longest bridges"; "26000 miles } \\
\text { of motorways" }\end{array}$ & & $\begin{array}{l}\text { ominous } \\
\text { music, } \\
\text { rhythmed } \\
\text { more and } \\
\text { more quickly }\end{array}$ \\
\hline
\end{tabular}

To start with, the presenter is interviewing some experts on economy, one of whom articulates "They just hit the accelerator button on investment". Soon the image is shifted to the skyscrapers in Wuhan with low angles. The special low angles give the buildings an overpowering feeling making them larger than life, indicating excessive investment rather than necessary. Subsequently, by compressing a long period of house constructions into a few seconds, the clip maps the characteristics of "insanity". Later, when the images of investment on public facilities construction change rapidly with an urgent voice, the motion of camera is accelerated and The Dark Knight theme music quickens like crazy to increase the thrill of speed. Finally, motorways appear, all means of traffic hastening and background color dimming.

The abstract idea of ECONOMY lies in the various means of transportation like metros, airports and motorways, i.e. CHINESE ECONOMY IS TRANSPORTATION. With the aid of articulations of experts and economists, camera perspectives and background music, the theme metaphor CHINESE INVESTMENT IS ACCELERATOR BUTTON (FOR TRANSPORTATION) is formed. The relationship between domains can be concluded as follows:

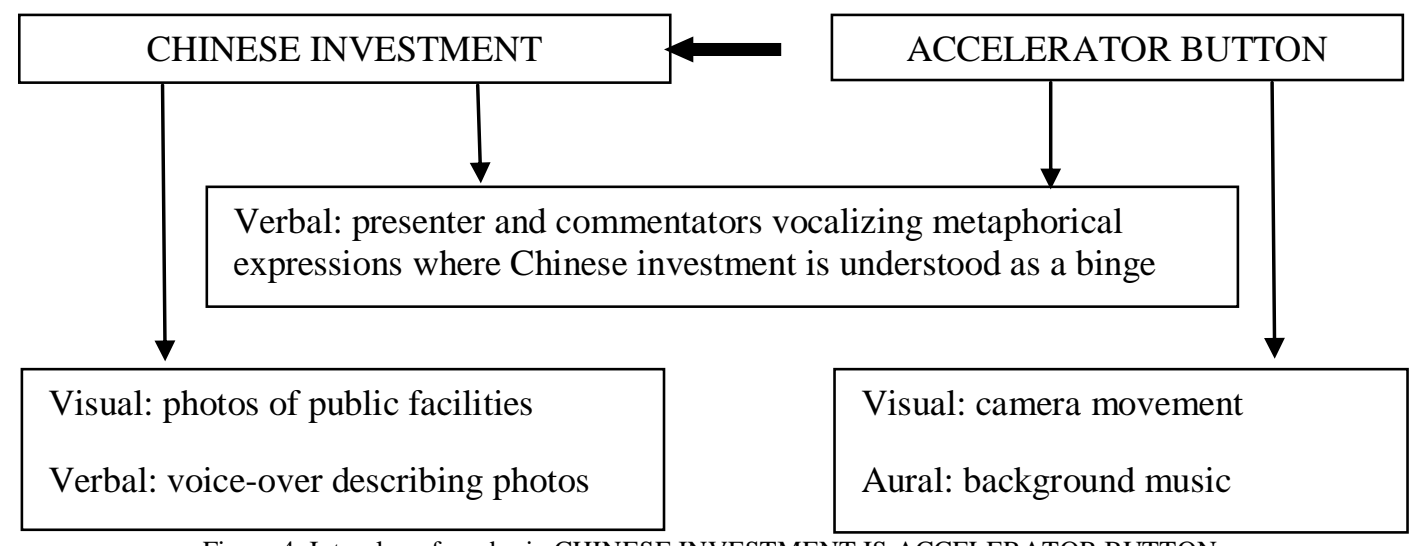

Figure 4. Interplay of modes in CHINESE INVESTMENT IS ACCELERATOR BUTTON.

Visually, the images of constructions of metros, airports and motorways are presented, which seem realistic and objective. Nonetheless, it is not the case when sub-modes are carefully examined. In the first shot in Table 3, the train in the tunnel is running speedingly with the time lapse effect, which resembles an explosion as a whole. Similarly, in the second shot, the viewer watches the train accelerating from the perspective of low angles, which exaggerate the speed of the train. In order to account for all the potential meaning of acceleration, the initial metaphor CHINESE ECONOMY IS TRANSPORTATION (receptor metaphor) is enriched with the conceptual structure provided by 
GAINING POWER IS MOVING FORWARD (donor metaphor), thus producing a metaphoric amalgam (for amalgamation, the reader may refer to Perez Sobrino 2017) ECONOMY GAINING POWER IS TRANSPORTATION MOVING FORWARD. AS the viewer might observe, the enriched version allows Chinese economy to inherit the negative attributes that go beyond the scope of those borrowed from the domain of transportation. According to Evans and Green's (2006) typology, the tunnel and track in the above images are containers. Since the contents keep gaining power, the containers might face the danger of being exploded. So far, the metaphor can be recapped: CHINESE ECONOMY IS OUT (OF CONTROL).

The other submodes ---- dimming background color and ominous background music added in post-production express the producer's denial attitude towards Chinese economy. Moreover, in the interview the words of economists sounded more reliable and convincing than those of the host. Here, the interviewed economists are metonymic for economy (HUMAN FOR NON-HUMAN). However, the six economists shown are unexceptionally western; therefore, Chinese economy is a subject of "otherness". The viewer might "receive" the negative evaluation without realizing the ideological bias.

2. Analysis of Type II

The second most frequent mapping is type II (verbal, visual and aural representations of the source mapping onto the implied target), as in the case of the following example.

A second instantiation is the conceptual metaphor CHINESE WOMEN EAGER FOR MARRIAGE ARE DOLLS in the second episode of Secrets of China. The situation under discussion happens in an underground shopping mall in Beijing. Table 4 includes the manifestations of the metaphor.

TABLE 4

ELEMENTS OF THE CM: CHINESE WOMEN EAGER For MARRIAGE ARE DOLLS

\begin{tabular}{|c|c|c|c|c|}
\hline Place & Settings & Verbal & Visual & Aural \\
\hline $\begin{array}{l}\text { the } 2^{\text {nd }} \\
\text { episode of } \\
\text { Secrets of } \\
\text { China. } \\
14: 37-15 \\
: 20\end{array}$ & $\begin{array}{l}\text { a shopping } \\
\text { mall in } \\
\text { Beijing }\end{array}$ & $\begin{array}{l}\text { presenter: "childish } \\
\text { tat"; "babyish"; } \\
\text { "obsessed with being a } \\
\text { white baby" }\end{array}$ & 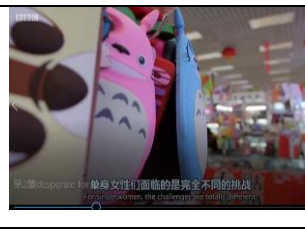 & $\begin{array}{lll}\text { song: } & \text { "He } & \text { only } \\
\text { wants you } & \text { when } \\
\text { you're 17." } & \end{array}$ \\
\hline Place & Settings & Verbal & Visual & Aural \\
\hline $\begin{array}{l}\text { the } 2^{\text {nd }} \\
\text { episode of } \\
\text { Secrets of } \\
\text { China. } \\
\text { 15:25-16 } \\
: 50\end{array}$ & $\begin{array}{l} \\
\text { the } \\
\text { presenter's } \\
\text { hotel in } \\
\text { Beijing }\end{array}$ & $\begin{array}{l}\text { presenter: } \\
\text { "Lolita-ish vibe"; } \\
\text { "pretty sick"; "like a } \\
\text { doll"; "incredibly } \\
\text { uncomfortable"; "like } \\
\text { a child"; } \\
\text { "fully-fledged Chinese } \\
\text { girl"; "an extreme } \\
\text { look"; "like an anime } \\
\text { character" }\end{array}$ & ва & $\begin{array}{l}\text { song: "Stayin' in } \\
\text { my place pretend/ } \\
\text { Where the fun ain't } \\
\text { got no end... Need } \\
\text { someone to numb } \\
\text { the pain" }\end{array}$ \\
\hline
\end{tabular}

The focal point of the episode "Desperate for Love" is that young Chinese people are longing to get married. Derived from the context, it is no difficult to identify the target domain CHINESE WOMEN EAGER FOR MARRIAGE. Nonetheless, the source domain is developed step by step in three real scenarios. The first scenario chosen by the presenter is an underground shopping mall selling a variety of female gadgets. As the camera foregrounds the baby-face phone covers, a doll with nipple in mouth and a baby-face blenching mask, the correlation between girls for marriage and babyish dolls is established. During the whole process, Ladytron's song Seventeen is playing now and then. Later in the second scenario, the presenter herself even goes great length to wear contact lens, eyelashes, butterfly hair band and to take selfie stick to claim her in full dress as a "fully-fledged Chinese girl", accompanied by the background song Stay High. The format of the interplay of the three modes in type IV can be drawn as follows: 


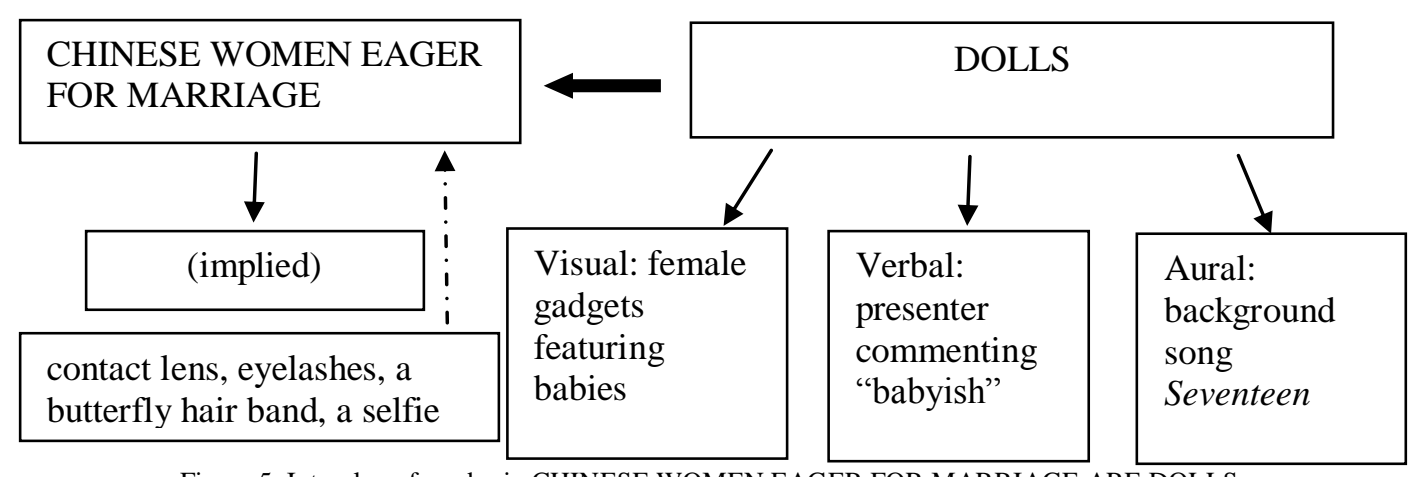

Figure 5. Interplay of modes in CHINESE WOMEN EAGER FOR MARRIAGE ARE DOLLS.

The above scenarios, though real, are deliberately selected. In the first one, there is a variety of commodities in the underground shopping mall but visually naïve female gadgets are chosen exclusively to appear in the documentary. Those selected scenarios are in line with the definition of a metaphor scenario "about 'typical' aspects of a source-situation, for example, its participants and their roles, the 'dramatic' storylines and outcomes, and conventional evaluation of whether they count as successful or unsuccessful, normal or abnormal, permissible or illegitimate" (Musolff, 2006, p. 28). Hence, these scenarios present an opportunity to better analyze the attributes of metaphors. Visually, the participant (Billie JD Porter pretending to be a Chinese woman) tries contact lens, eyelashes, butterfly hair band and selfie stick. Besides the visual mode, what the presenter comments as "childish" or "babyish" adds more impact to the source domain, which echoes the criterion concluded by the presenter at the beginning of the episode that guys are after girls in their early 20s. In aural mode, Ladytron's song Seventeen, originally denouncing the phenomenon that teenagers are manipulated as a commodity, is a special indictment of a commodity of disposable dolls. From the intended metaphor, the entailed message is that Chinese women are dolls to be played and disposed by their future husbands, which is an abnormal view of marriage, a rigid stereotype towards Chinese people.

\section{Summary}

Based on the analysis of multimodal manifestation of the cases in the self-built corpus, this chapter discovers that the representation of multimodal metaphors in the specific genre of documentary manifests themselves with some unique properties.

First, 91\% metaphors in the corpus are conveyed via multiple modalities, which supports the claim that communication rarely happens via one channel only, especially if more modes are available, as in case with documentaries. Second, of eighty-three multi-mappings, two-mode interaction occupies only ten whereas the other seventy-three belong to three-mode mappings involving visual, verbal and aural modes. Among the three-mode mappings, the most typical representations are type I (verbal, visual and aural representations of the source mapping onto verbal and visual representations of the target) and type II (verbal, visual and aural representations of the source mapping onto the implied target). At the same time, the least fractions are type $\mathrm{X}$ and type XI where both the source domains are absent. It proves documentaries tell not necessarily the truth, but a reconstruction. Since the constructive message in the sources is intended for the viewer, the metaphors that draw on absent sources are rare. Forceville (2007) notes that "apart from their greater degree of comprehensibility, metaphors drawing on images, sounds, and music... have a more intense, immediate emotional impact than verbal ones" (p. 15-34). Therefore, the documentary exploits various visual, aural and verbal elements that are interactive with and dependent upon each other to impress the viewer and finally influence what they think.

\section{IDeOlogical Evaluation of Multimodal Metaphors}

As is analyzed previously, the working mechanism of those identified metaphors suggests that potentially the reality is reconstructed in media. The questions, then, are "What are the underlying messages in the press discourse, and whose interests do these messages serve?" These are fundamentally questions about ideology because they suggest that media are places where certain ideas are effectively hidden or highlighted. Ideology in this paper is not just about politics but gives people an understanding of how they should decide more specific issues.

When decoding the construction of China's images in those BBC documentaries, two characteristics of conceptual metaphors should be taken into consideration: 1) metaphor is evaluative; 2) metaphor is culturally-embedded. This paper is going to reveal ideologies subtly hidden behind the metaphorical veil by examining the choice of source domain and then determining whether the metaphorical entailments are positive, neutral, negative or culturally misreading. This method of reasoning has been carried out for all seventeen metaphors (see Table 5). 
TABLE 5

ENTAILMENTS OF THE THEME METAPHORS IN THE CORPUS

\begin{tabular}{|c|c|c|}
\hline Metaphors & Entailments & Polarity \\
\hline $\begin{array}{l}\text { CHINESE KITCHEN IS } \\
\text { BATTLEFIELD }\end{array}$ & $\begin{array}{l}\text { A Chinese kitchen is chaotic, unfriendly and wild; } \\
\text { Cooking in a Chinese kitchen is dangerous and brutal. }\end{array}$ & $\begin{array}{l}\text { negative \& } \\
\text { culturally } \\
\text { misreading }\end{array}$ \\
\hline $\begin{array}{l}\text { CHINESE ECONOMY IS } \\
\text { MOVEMENT }\end{array}$ & $\begin{array}{l}\text { Chinese economy has such an explosive growth that it gets out of } \\
\text { control. }\end{array}$ & negative \\
\hline $\begin{array}{l}\text { CHINESE INVESTMENT IS } \\
\text { BINGE }\end{array}$ & $\begin{array}{l}\text { The speed and scale of Chinese investment is so excessive that it is } \\
\text { doomed to fail. }\end{array}$ & negative \\
\hline CHINESE CREDIT IS GAMBLE & $\begin{array}{l}\text { It is risky for the credit to control Chinese economy; } \\
\text { Chinese credit is sinister. }\end{array}$ & negative \\
\hline $\begin{array}{l}\text { THE DIFFERENCE BETWEEN } \\
\text { CHINESE AND BRITISH } \\
\text { EDUCATION SYSTEM IS } \\
\text { CONFLICT }\end{array}$ & $\begin{array}{l}\text { Chinese education is boring, rigid and ruthless while British } \\
\text { education is interesting, lively and motivating; } \\
\text { Chinese and British education are incompatible. }\end{array}$ & negative \\
\hline $\begin{array}{l}\text { CHINESE SCHOOL IS MILITARY } \\
\text { CAMP }\end{array}$ & $\begin{array}{l}\text { In a Chinese school, discipline and conformity are stressed; } \\
\text { Chinese students are trained to be respectful and obedient through } \\
\text { extremely harsh schooling. }\end{array}$ & negative \\
\hline $\begin{array}{l}\text { CHINESE CLASS IS REPETITIVE } \\
\text { DRILL }\end{array}$ & $\begin{array}{l}\text { Chinese students' personality and autonomy are ignored; } \\
\text { Chinese students learn passively. }\end{array}$ & negative \\
\hline CHINESE GAMING IS ESCAPING & $\begin{array}{l}\text { Chinese people game to refrain from study, work, reality and social } \\
\text { system }\end{array}$ & negative \\
\hline $\begin{array}{l}\text { CHINESE MARRIAGE IS } \\
\text { BUSINESS }\end{array}$ & $\begin{array}{l}\text { Chinese people get married for material lives, not necessarily for } \\
\text { love; } \\
\text { There is an uncertainty of risk in marriage when competition is } \\
\text { open. }\end{array}$ & negative \\
\hline CHINESE MARRIAGE IS SHOW & $\begin{array}{l}\text { Chinese couples present their marriage to the best advantage to } \\
\text { show off their wealth and status but it is usually not true }\end{array}$ & negative \\
\hline $\begin{array}{l}\text { CHINESE WOMEN EAGER FOR } \\
\text { MARRIAGE ARE DOLLS }\end{array}$ & $\begin{array}{l}\text { In order to increase the potential of getting married, Chinese } \\
\text { women endeavor to please Chinese guys' taste in young ladies. }\end{array}$ & negative \\
\hline CHINESE HISTORY IS CYCLE & $\begin{array}{l}\text { Each dynasty rises to a peak and then falls, only to be replaced by a } \\
\text { new dynasty. }\end{array}$ & neutral \\
\hline $\begin{array}{l}\text { CHINESE LIFE IS FLOATING } \\
\text { WATER }\end{array}$ & Chinese people in history led unpredictable and instable lives. & neutral \\
\hline $\begin{array}{l}\text { THE WEST IS NEW KNOWLEDGE } \\
\text { AND CHINA IS ILLITERACY }\end{array}$ & $\begin{array}{l}\text { Chinese tradition is nothing compared to Western invention; } \\
\text { The British were open-minded while Chinese people were ignorant. }\end{array}$ & negative \\
\hline CHUNYUN IS MIGRATION & $\begin{array}{l}\text { A massive number of Chinese people are on the move during the } \\
\text { Spring Festival travel season. }\end{array}$ & $\begin{array}{l}\text { neutral \& } \\
\text { culturally } \\
\text { misreading }\end{array}$ \\
\hline CHUXI DINNER IS PARTY & Chinese people reunite, talking, drinking and eating on Chuxi. & $\begin{array}{l}\text { neutral \& } \\
\text { culturally } \\
\text { misreading }\end{array}$ \\
\hline $\begin{array}{l}\text { NEW YEAR CELEBRATION IS } \\
\text { PARTY }\end{array}$ & $\begin{array}{l}\text { Chinese people go out to have fun in a carnival and entertaining } \\
\text { atmosphere. }\end{array}$ & $\begin{array}{l}\text { neutral \& } \\
\text { culturally } \\
\text { misreading }\end{array}$ \\
\hline
\end{tabular}

As is seen above, of seventeen theme metaphors summarized from six China-related documentaries, five are neutral and twelve are negative. Although there is a trend for the $\mathrm{BBC}$ to assume a neutral attitude towards Chinese culture and history, the images constructed by BBC documentaries are still largely negative from the choice of source domain and metaphorical mapping: madly-growing Chinese economy posing a threat to the world, militarized Chinese education producing students with sharp memories, standardized social mainstream leading to a lack of freedom, competitive marriage market driving young people to go extreme, etc.

At least two reasons account for the negativity. First, bias has been a feature of the mass media since its birth. To satisfy the curiosity of viewers who do not know much about China, the BBC may deliberately exaggerate the distinction between the West and China. For instance, Are Our Kids Tough Enough? Chinese School highlights the rotting learning to such degree that it deletes all the scenes of interaction and cooperation between teachers and students. In Exploring China: A Culinary Adventure, the presenters use the verbs which do not normally appear in a cuisine program to impact the viewer. Second, to be in line with the long-stereotyped images of China, the BBC may consciously or unconsciously manipulate the documentaries to appeal to the viewer, especially the Westerners. For example, the title How China Fooled the World could be seen as being manipulative since the documentary clearly has an agenda to oppose Chinese economy. No matter what efforts the Chinese government has made to rescue China from the crisis, Chinese economic growth is labeled as greedy and menacing. Also, in Secrets of China, the presenter directly asks the interviewee the question "Do you think that the lack of freedom here leads to people being unhappy?" In fact, throughout the episode no sign suggests that people are unhappy. In this way, the negative image of China could easily resonate in western viewer, who holds prejudices against the heterogeneous culture out of cultural hegemonism.

Even for the neutral metaphors, they are mainly simplistic and superficial expression of Chinese image. In Chinese New Year: The Biggest Celebration on Earth, the source domain PARTY is used for both Chuxi dinner and New Year celebration, shielding viewer from deep significance of Chinese New Year. And in the metaphor CHUNYUN IS 
MIGRATION, the movement of a number of people is highlighted but the family-oriented value is hidden. In a word, Chinese New Year is still the new year in others' eyes, not Chinese people's.

\section{CONCLUSION}

Firstly, the present paper investigates the unique characteristics of representation in the specific genre of documentary. In most occasions, the tension of a metaphor lies between literal source domain and underlying target domain; however, the research data in this paper prove that the target domains are directly pinpointed while the source domains are craftily designed in the documentaries. The cognitive operation of the metaphors suits the specificities of documentary as a genre.

Secondly, the analyses have demonstrated that various sub-modes such as editing, music, dubbing sound, colors and camera perspective are used in the source domains as an overall persuasive strategy. Those sub-modes are always considered as the carrier of additional elements that help the formulation of the conceptual metaphors; however, the data suggest that they have their own power to structure one concept in terms of another. Music is always considered as the carrier of additional elements that help the formulation of the CMs but the data in this paper suggest that music has its own power to structure one concept in terms of another. For instance, without the filmic theme music of The Great Escape and The Dam Busters, the source domains such as "conflict", "military camp" or "military drill" will not be cued. All in all, the sources are largely dependent on the non-diegetic efforts to deliver the values.

Thirdly, with the choices of source domains and the mapping mechanism, most multimodal metaphors in these selected documentaries present China with negative narratives (negative metaphors accounts for $71 \%$ of the entire data): an irresponsible economic superpower, a regiment with a draconian education system, a civilization with constant emergency of social problems. The BBC may intentionally or unintentionally highlight certain negative attributes mapped to the images of China, which ultimately lead the public to conceptualizing China negatively. Decoding the use of multimodal metaphors can raise consciousness about how press discourse contains underlying ideologies and on the other hand avoid the stereotype and bias of the images of a particular country. The ideological analysis of multimodal metaphors provides a window onto what kinds of ideas circulate through media and how they are constructed, displayed and sometimes reworked.

The entailments of some multimodal metaphors drawn from these documentaries might generate misunderstanding of Chinese culture. For instance, in the case of Exploring China: A Culinary Adventure, the intense atmosphere of a Chinese kitchen is highlighted but the connotation of hong huo is ignored. Also, during Chinese New Year: The Biggest Celebration on Earth, both Chuxi and Chinese New Year celebration are oversimplified as PARTY, whereas the core ideal of family value does not reach the viewer. Those misinterpretations may be excluded if documentary producers look at culture from a cognitive perspective.

\section{REFERENCES}

[1] Aitken, I. (2006). Encyclopedia of the Documentary Film. London: Routledge.

[2] Catalano, T. \& L. R. Waugh. (2013). The Ideologies Behind Newspaper Crime Reports of Latinos and Wall Street / CEOs: A Critical Analysis of Metonymy in Text and Image. Critical Discourse Studies, 10(4), 406-426.

[3] Catalano, T. \& L. R. Waugh. (2016). Representations of Power: A Critical Multimodal Analysis of U.S. CEOs, the Italian Mafia and Government in the Media. Journal of Language and Politics, 15(6), 790-817.

[4] Charteris-Black, J. (2004). Corpus Approaches to Critical Metaphor Analysis. London: Palgrave Macmillan.

[5] De los Ríos, ME Cortés. (2010). Cognitive devices to communicate the economic crisis: an analysis through covers in The Economist. Iberica 20, 81-107.

[6] Evans, V. \& M. Green. (2006). Cognitive Linguistics: An Introduction. New Jersey: Lawrence Eribaum.

[7] Fairclough, N. (1995). Critical discourse analysis: the critical study of language. London and New York: Longman.

[8] Forceville, C. J. (2006). Non-verbal and multimodal metaphor in a cognitivist framework: Agendas for research. Applications of Cognitive Linguistics, 1, 379-402.

[9] Forceville, C. J. (2007). Multimodal metaphor in ten Dutch TV commercials. Semiotics, 1 (1), 15-34.

[10] Forceville, C. J. \& E. Urios-Aparisi. (2009). Multimodal Metaphor. New York: Mouton de Gruyter.

[11] Hart, C. (2008). Critical discourse analysis and metaphor: toward a theoretical framework. Critical Discourse Studies, 5 (2), 91-106.

[12] Hidalgo-Downing, L. \& B. Kraljevic-Mujic. (2011). Multimodal metonymy \& metaphor as complex discourse resources for creativity in ICT advertising discourse. Review of Cognitive Linguistics, 9 (26), 153-178.

[13] Johnson, M. (1983). Metaphorical Reasoning. Southern Journal of Philosophy, 21(3), 371-389.

[14] Johnson, M. (1993). Moral Imagination: Implications of Cognitive Science for Ethics. Chicago: University of Chicago Press.

[15] Kress, G. \& T. van Leeuwen. (2006). Reading Images: The Grammar of Visual Design. London: Routledge.

[16] Lakoff, G. (1993). The contemporary theory of metaphor. In A. Ortony (Eds.), Metaphor and thought. Cambridge: Cambridge University Press, 202-251.

[17] Lakoff, G. (2002). Moral Politics: How Liberals and Conservatives Think. Chicago: University of Chicago Press.

[18] Lakoff, G. \& M. Johnson. (1980). Metaphors We Live By. London: The University of Chicago Press.

[19] Lakoff, G. \& M. Johnson. (1999). Philosophy in the flesh. New York: Basic Books.

[20] Liu, Y. (2017). Multimodal metaphorical representation in educational TV advertisements. Foreign language and translation, 24(1), 50-56. 
[21] Maalej , Z. (2007). Doing critical discourse analysis with the contemporary theory of metaphor: Towards a discourse model of metaphor. In H. Christopher \& D. Lukes (Eds.), Cognitive Linguistics in Critical Discourse Analysis. Newcastle: Cambridge Scholars Publishing, $132-158$.

[22] Musolff, A. (2006). Metaphor scenarios in public discourse. Metaphor and Symbol, 21(1), 23-38.

[23] Musolff, A. (2012). The Study of metaphor as part of critical discourse analysis. Critical discourse studies, 9(3): 301-310.

[24] Musolff, A. (2016). Political Metaphor Analysis: Discourse and Scenarios. London: Bloomsbury.

[25] Perez-Sobrina, P. (2017). Multimodal Metaphor and Metonymy in Advertising. Amsterdam/ Philadelphia: John Benjamins Publishing Company.

[26] Song Hongyu. (2018). An analysis of BBC documentary Are our kids tough enough from the perspective of cross-culture communication. Journalism Lover, 5, 50-53.

[27] Van Leeuwen T. (2005). Introducing Social Semiotics. London: Routledge.

[28] Wang, S. S. (2017). Visualizing China Through the Lens of the West: A Critical Analysis of British TV Documentaries on China. Ph.D. dissertation, Durham University.

[29] Xuan, Li, and Q. F. Wang. (2019). On Chinese discourse in BBC documentaries. Contemporary TV, 06, 68-72.

[30] Xu, Y. Y. (2015). An Analysis of the Prismatic Refraction of the TV Media on the Nation Image - Based on a Case of a BBC Documentary The Chinese Are Coming. Jinan Journal (Philosophy and Social Sciences), 37(10):131-137+164.

[31] Zhao, X. F. \& W. Feng. (2017). The Construction of China Image by Multimodal Metaphtonymy Complex: A Case of China-related Political Cartoon Discourses. Journal of Xi' an International Studies, 25(2), 31-36.

[32] Zhu, G. S. \& J. B. Huang. (2017). A research to Chinese youth image in western mainstream media--- a critical discourse analysis of BBC documentary Chinese secrets. China Youth Study, 5:106-111.

Ping Tang was born in Hunan, China in 1984. She received her Master's degree in Linguistics and Applied Linguistics from Guilin University of Technology, China, in 2018.

She is currently a lecturer in the School of Foreign Studies, Guilin University of Technology, China. Her research interests include cognitive linguistics and multimodality.

She has published articles in some peer-reviewed Chinese journals.

Kelin Quan was born in Guangxi, China in 1974. He received his Ph.D. in international studies from Nanjing University, China in 2002.

He is currently dean and professor at the College of International Education, Guilin University of Technology, China. His research interests include English language and culture, and translation studies.

Dr. Quan is an executive member of China Association for Studies of Translation History.

Jianbin Zhu was born in Sichuan, China in 1978. He is a PhD student in the School of International Studies at University of International Business and Economics, and an associate professor of linguistics at Guilin University of Technology.

His main research interests are in cognitive linguistics, discourse studies and multimodality.

Mr. Zhu is the principal investigator of Guangxi Philosophy and Social Science Research Program (Grant No. 18BYY005) and Innovation Project of Guangxi Graduate Education (Grant No. JGY2019099). He has published articles in Multimodal Communication and some other peer-reviewed Chinese journals. 